\title{
Stromal-cell-derived Factor 1- $\alpha$ Promotes Tumor Progression in Colorectal Cancer
}

\author{
Se Jun Park, Tae Sung Ahn, Sung Woo Cho, Chang Jin $\mathrm{Kim}^{1}$, Dong Jun Jung ${ }^{1}$, Myung Won Son, \\ Sang Ho Bae, Eung Jin Shin², Moon Soo Lee, Chang Ho Kim, Moo Jun Baek \\ Departments of Surgery and ${ }^{1}$ Pathology, Soonchunhyang University College of Medicine, Cheonan; ${ }^{2}$ Department of Surgery, Soonchunhyang \\ University Bucheon Hospital, Soonchunhyang University College of Medicine, Bucheon, Korea
}

Purpose: Although stromal-cell-derived factor (SDF)-1 $\alpha$ is suggested to be involved in tumorigenicity and tumor angiogenesis, the clinicopathological significance of its expression in colorectal cancers is not fully understood. We examined SDF-1a expression in colorectal cancers and investigated its relationship to clinicopathological features such as tumor staging, lymph-node metastasis, vascular invasion (VI), lymphatic invasion (LI) and neural invasion (NI).

Methods: Specimens of 83 primary colorectal cancers were examined immunohistochemically, and the relationships between clinicopathological features and SDF-1a expression were analyzed. To compare the expressions between the normal colon tissue and colorectal cancer tissues, we performed Western blot analyses.

Results: According to the Western blot analyses, SDF-1a was more highly expressed in colorectal carcinoma tissues than in normal colonic mucosa (20/21). According to the immunohistochemical stain, SDF-1 $a$ was associated with nodal status, distant metastasis, tumor staging, VI and LI. SDF-1 $\alpha$ expression had a significant prognostic value for overall survival. Kaplan-Meier plots of survival in patients with high SDF-1 $\alpha$ showed that high SDF-1 1 expression was associated with a shorter overall survival. However, no association was found between SDF-1a expression and other pathologic or clinical variables, including age, gender, degree of differentiation, and presence of perineural invasion.

Conclusion: The expression of SDF-1 $\alpha$ might be associated with tumor progression in colorectal cancer. Inhibition of SDF-1a could be a therapeutic option in colorectal cancer patients.

\section{Keywords: Colorectal neoplasms; Survival; Prognostic factor; SDF-1 $\alpha$; Chemokine CXCL12}

\section{INTRODUCTION}

Colorectal cancer is a very common malignant tumor not only in Korea but at the global level, and it is one of key causes of cancerinduced death [1]. In cases of localized colon cancer, the 5-year survival rate is nearly 82 to $93 \%$, but, once any metastasis incurs,

Received: August 31, 2011 Revised: October 18, 2011

Accepted: October 20, 2011

Correspondence to: Moo Jun Baek, M.D.

Department of Surgery, Soonchunhyang University Cheonan Hospital, Soonchunhyang University College of Medicine, 31 Suncheonhyang 6-gil, Dongnam-gu, Cheonan 330-930, Korea

Tel: +82-41-570-3633, Fax: +82-41-571-0129

E-mail: ssurge@sch.ac.kr

(C) 2012 The Korean Society of Coloproctology

This is an open-access article distributed under the terms of the Creative Commons Attribution NonCommercial License (http://creativecommons.org/licenses/by-nc/3.0) which permits unrestricted noncommercial use, distribution, and reproduction in any medium, provided the original work is properly cited. the prognosis can become very bad, causing the 5-year survival rate to drop below $10 \%$ [2]. In 30 to $40 \%$ of patients, liver metastases is found during the diagnosis while in from $50 \%$ of the patients, extrahepatic metastases are found in the lung, the peritoneum, and lymph nodes [3].

The cause of death in patients with colorectal cancer is mostly uncontrollable metastatic lesions. Among them, the liver is the organ most frequently subjected to metastases, and if such metastases occur, surgical resection is the only way to enhance the patient's survival rate. However, in recent days, even patients with liver metastasis, owing to development of various treatment methods, the patient's 5-year survival rate can be improved to $58 \%$ [4].

The process of cancer metastasis involves a sequence of several individual phases, and such sequential phases are all required to form metastatic cancers. Especially, angiogenesis around the tumor cells is known to play an important role in the progression and the metastasis of cancer [5]. Vasculogenesis and angiogenesis are known to contribute to forming the vasculature of the tumor 
in malignancies and to its expansion, consequently helping the growth of malignancies. Also, as a mechanism of angiogenesis that affects the growth of a malignant tumor, stem cells or precursor cells of bone marrow have been verified to migrate to the tumor where they differentiate into endothelial cells and become involved in the angiogenesis of the tumor [6].

Incorporation of bone marrow cells into the vascular endothelial lining has been reported for Lewis lung carcinomas and lymphomas, mammary adenocarcinomas, and gliomas [7-9]. Direct differentiation of stem/precursor cells is known to be important for revascularization after wound healing or ischemia of tissues whereas whether these cells have any critical roles in the vasculature expansion of a tumor is still unclear [10].

Various kinds of cytokines, such as granulocyte colony-stimulating factor, placental growth factor and stromal-cell-derived factor-1 (SDF-1), are known to cause mobility or chemotaxis of bone marrow stem/precursor cells, and among them, SDF-1 has a function to specifically control chemotaxis of cell groups that express CXCR4 receptor, such as CD34+ stem/precursor cells [11]. SDF-1 controls engraftment of hematopoietic stem cells inside the bone marrow in the embryogenesis period or in the adult period. In addition, this chemokine has been known to stimulate the gathering of endothelial precursor cells to ischemic areas and as a result, to contribute to neovascularization $[12,13]$.

Recently, a fact was identified that SDF-1 chemokine and its receptor play notable roles in the onset and the progression of primary or metastatic cancer from various organs [14-16]. Many studies indicate that SDF-1 $\alpha$ and its receptor CXCR4 play major roles in the formation of tumors as these substances have been identified as having very important roles in survival and proliferation, chemotaxis, migration and adhesion of cells [17]. The authors aimed to investigate the expression of SDF-1a protein in colorectal cancer tissues based on the aforementioned results and to identify what kinds of roles these substances have in colorectal cancer by comparing the expressions of SDF-1a protein and various clinicopathological factors of patients with colorectal cancer.

\section{METHODS}

\section{Subjects}

The study included 83 patients with colon cancer on whom a radical resection of the primary tumor was performed at Soonchunhyang University Cheonan Hospital from January 2003 to August 2006. Investigations addressed the ages of the patients, gender, stage, and distant metastasis. From pathology reports, the degree of differentiation, the invasion depth of the primary cancer, lymphnode metastasis and survival rate were investigated. The clinical profiles of the patients were investigated in a retrospective manner based on their medical records.

The stages of disease were classified according to the tumor-nodemetastasis (TNM) staging system by using the Classification version 7 published by the American Joint Committee on Cancer. A 5-year follow-up was conducted to identify the survival rate.

\section{Western blot}

Cell lysates were prepared using radioimmunoprecipitation assay buffer ( $1 \times$ phosphate-buffered saline [PBS], pH 7.2, 0.5\% sodium deoxycholate, $1 \%$ Nonidet P-40, $0.1 \%$ sodium dodecyl sulfate). In this method, the protein $(40 \mu \mathrm{g} / \mathrm{lane})$ was isolated from NuPAGE 4 to $12 \%$ bis-trisployacrylamide gels (Invitrogen, Carlsbad, CA, USA) and sent to an Immuno-Blot polyvinylidene fluoride membrane by electrophoresis. Thereafter, the membranes were incubated at room temperature for 1 hour by using anti-SDF- $1 \alpha$ antibody (R\&D Systems Inc., Minneapolis, MN, USA) in a 1:500 dilution. Then, a reaction was induced for horseradish-peroxidaseconjugated secondary antibody in a 1:5,000 diluted solution while the signals were visualized using an enhanced chemiluminescent detection kit. $\beta$-actin was also studied by using the aforementioned procedures.

\section{Immunohistochemical staining}

Sample tissues taken from colon cancer were fixed in 10\% neutral buffered formalin solution and prepared using the method with routine use of paraffin blocks. In order to perform the immunohistochemical staining for SDF-1 $\alpha$, a 4-mm-thinck paraffin block was de-paraffined, re-moisturized and placed in 0.01-M citrate buffer solution, with subsequent heating by using ultrashort waves for 15 minutes. The sections were reacted with a mixture of methanol and $0.3 \% \mathrm{H}_{2} \mathrm{O}_{2}$ in methanol for 20 minutes at room temperature in order to remove the intrinsic peroxidase activity. As the next step, the sections were immunohistochemically stained using an UltraTech Kit (Immunotech, Marseille, France) according to the instructions from the manufacturer. The sections were pretreated with $1 \%$ bovine serum albumin in PBS and were reacted to anti-SDF-1 $\alpha$ antibody (dilution 1:50; R\&D Systems Inc.) for 1 hour at room temperature. Thereafter, the sections were reacted to biotinylate secondary antibody for 15 minutes, washed with PBS, and treated with peroxidase-conjugated streptavidin for 20 minutes. Finally, the sections were reacted to 3, 30-diaminobenzidine tetrahydrochloride containing $0.05 \% \mathrm{H}_{2} \mathrm{O}_{2}$ for 3 minutes and counterstained with hematoxylin. Sections of esophageal cancer identified with excessive expression of protein were used as the positive control group, but were not applied to the negative control group.

\section{Evaluation of immunohistochemical staining}

In the immunohistochemical staining using SDF-1a antibody, depending on the intensity of staining on the cytoplasm of SDF-1 $\alpha$, the expression was classified by reading into 2 groups: weak expression and strong expression. The intensity of staining was into strong positive $(3+)$, weak positive $(1+)$, and negative (0). 0 and $1+$ were determined as weakly expressed while $2+$ and $3+$ were determined as strongly expressed. The readings were carried out by two specialized pathologists, each of whom generated respec- 
tive reading results, and if they had different results for one reading, they consulted to derive one conclusion.

\section{Statistical analysis}

The statistical analysis was performed using SPSS ver. 17.0.1 (SPSS Inc., Chicago, IL, USA). In the data analysis, the chi-square test was used to analyze the correlation between SDF-1 $\alpha$ and clinicopathological factors such as the intensity of SDF-1a staining, the gender, the age, the stage of disease (pTNM) and the degree of differentiation on the final biopsy report, as well as the presences of vascular invasion, lymphatic invasion and neural invasion. The survival rate was analyzed using the Kaplan-Meier method and was subsequently assessed by using the log-rank test.

Table 1. Patients characteristics

\begin{tabular}{lc}
\hline Characteristic & No. of cases $(\%)$ \\
\hline Sex & \\
Female & $46(55.4)$ \\
Male & $37(44.6)$ \\
Age & \\
$<60$ & $35(42.2)$ \\
$\geq 60$ & $48(57.8)$ \\
T stage & \\
T1 & $3(3.6)$ \\
T2 & $7(8.4)$ \\
T3 & $69(83.1)$ \\
T4 & $4(4.8)$ \\
Nodal status & \\
N0 & $32(38.6)$ \\
N1 & $27(32.5)$ \\
N2 & $24(28.9)$ \\
Stage & \\
I & $9(10.8)$ \\
II & $25(30.1)$ \\
III & $44(53.1)$ \\
\hline IV & $5(6.0)$ \\
\hline
\end{tabular}

\section{RESULTS}

\section{Clinical characteristics}

The mean age of the 83 patients with colorectal cancer was 61 years (range, 20 to 82 years) old. By gender, 37 (44.6\%) were male, and $46(55.4 \%)$ were female. By the stage of disease, $9(10.8 \%)$ were at stage I, $25(30.1 \%)$ were at stage II, $44(53.1 \%)$ were at stage III and $5(6.0 \%)$ were at stage IV. By the T stage, 3 (3.6\%) were T1, 7 (8.4\%) were T2, $69(83.1 \%)$ were T3 and $4(4.8 \%)$ were T4. The number of negative lymph-node metastases was 32 (38.6\%); N1 was 27 (32.5\%), and N2 was 24 (28.9\%) (Table 1).

\section{Results of Western blot}

When Western blot tests were performed using the normal colonic mucosa and colorectal cancer tissues, it was possible to observe that SDF-1a was more highly expressed in the colorectal cancer tissues in 20 cases out of 21 cases (Fig. 1).

\section{Immunohistochemical results of SDF-1a}

When the immunohistochemical staining was performed on SDF-1 $a$ by using paraffin-embeddedcolorectal cancer tissues (Fig. 2 ), out of 83 subjects, the number of cases with no expression of SDF-1a (normal, negative) was 4 (4.8\%), that of weak expression $(1+)$ was $22(26.5 \%)$, thatof moderate expression $(2+)$ was 19 (22.9\%), and that of strong expression (3+) was 38 (45.8\%). When the unstained cases and the patients with weak response to staining were categorized as the weak positive group and the patients with moderate and strong staining were categorized as the strong positive group, the former had 26 subjects (31.1\%), and the latter had 57 subjects $(68.9 \%)$ (Table 2$)$.

\section{Correlation between SDF-1 $\alpha$ expression and clinicopathological factors}

When the correlations between the intensity of SDF-1a staining and several clinical parameters were analyzed, the results showed that the degree of T staging and the differentiation of cancer tissues had no statistically significance correlation with the expression of SDF-1 $\alpha$. Nevertheless, among the 57 patients in the group with strong expression of SDF-1 1 , lymph-node metastasis was present in 44 cases $(77.1 \%)$, and among the 26 patients in the group

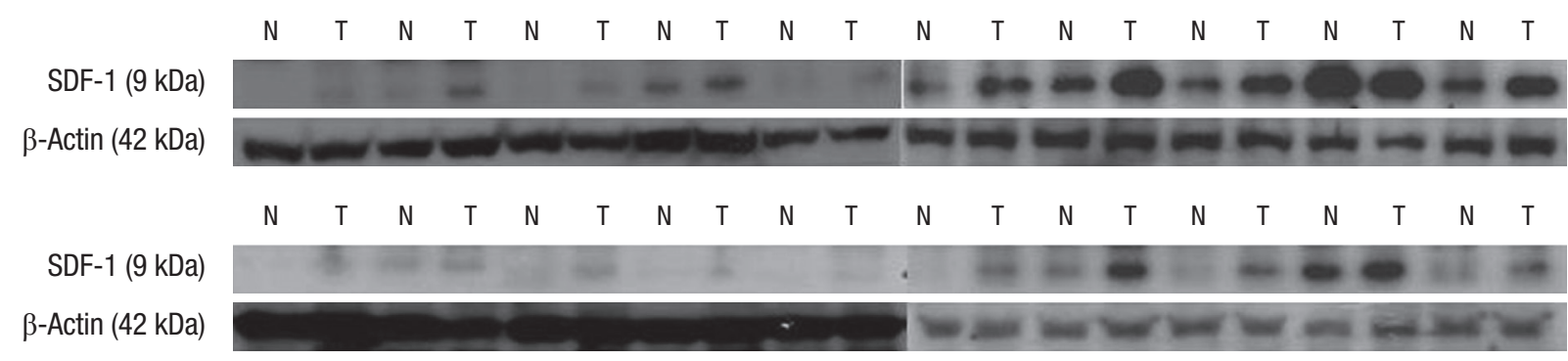

Fig. 1. Expression of stromal-cell-derived factor (SDF)-1a in malignant and non-malignant colorectal tissues. N, normal tissues; T, cancer tissues. 

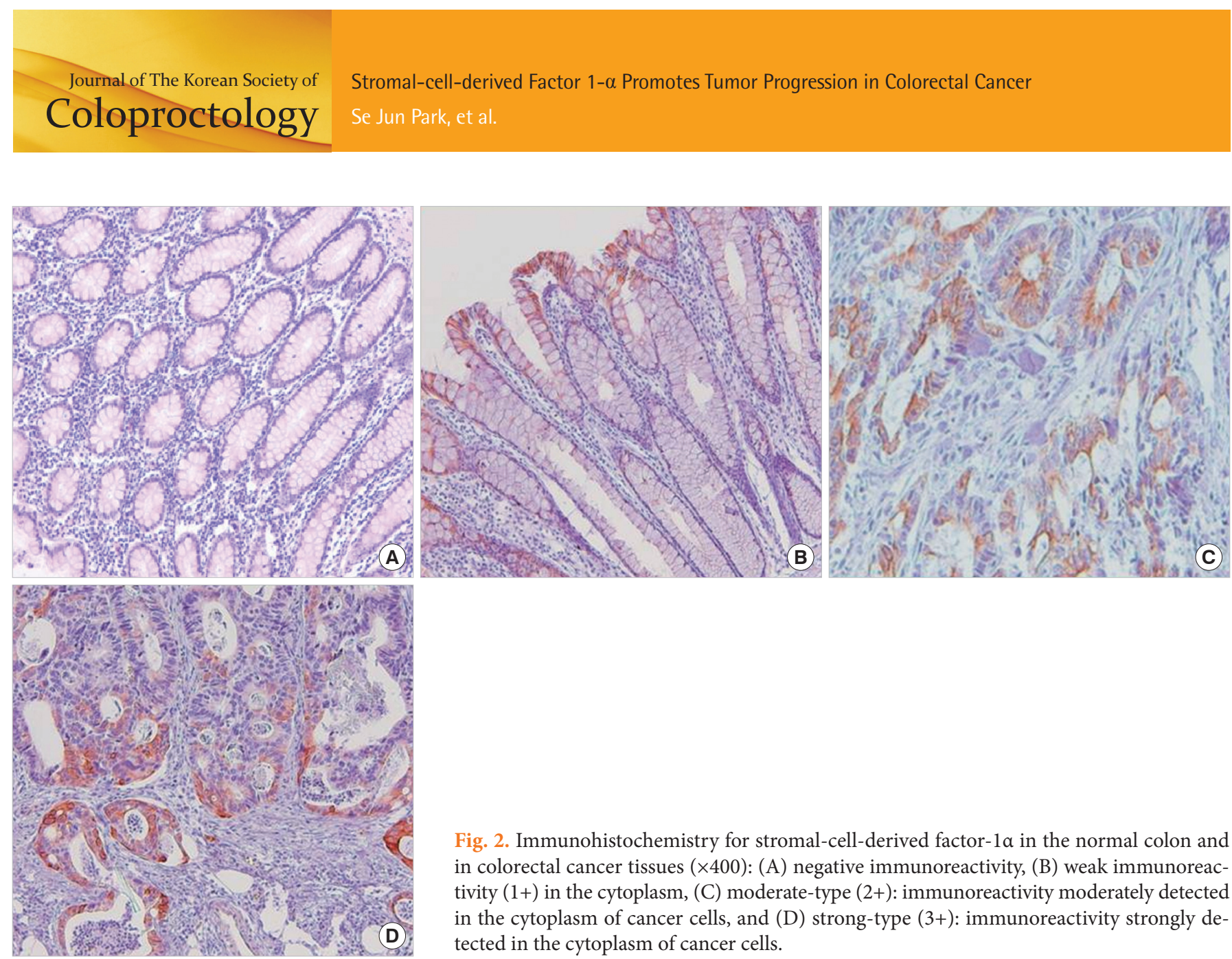

Fig. 2. Immunohistochemistry for stromal-cell-derived factor-1 $\alpha$ in the normal colon and in colorectal cancer tissues ( $\times 400)$ : (A) negative immunoreactivity, (B) weak immunoreactivity $(1+)$ in the cytoplasm, (C) moderate-type $(2+)$ : immunoreactivity moderately detected in the cytoplasm of cancer cells, and (D) strong-type (3+): immunoreactivity strongly detected in the cytoplasm of cancer cells.

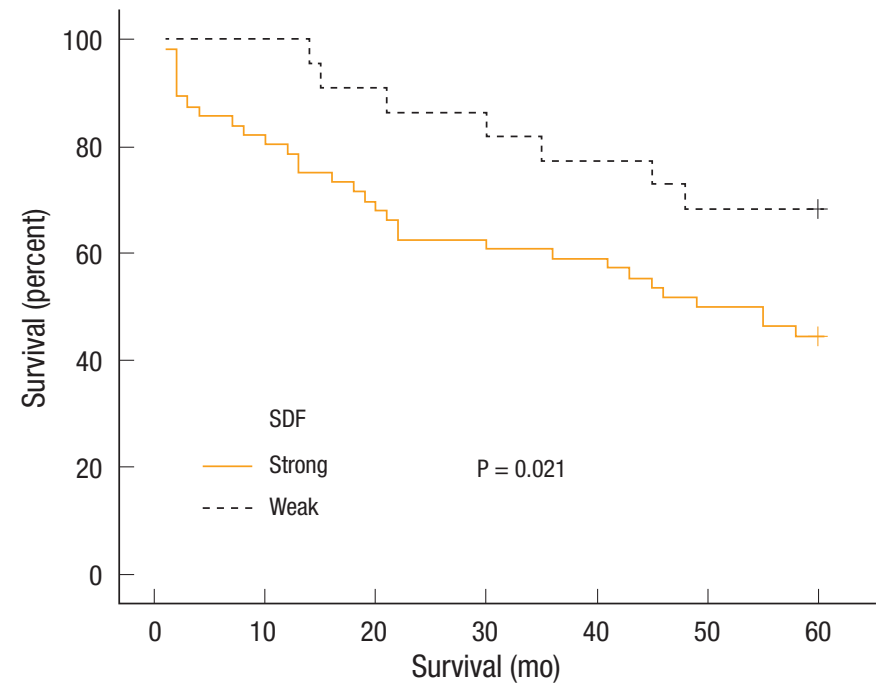

Fig. 3. Kaplan-Meier survival curves for weak and strong stromal-cellderived factor (SDF)-1 $\alpha$ expression in cases of colorectal cancer.

with weak expression of SDF-1 $\alpha$, lymph-node metastasis was present in 19 cases $(73.1 \%)$, indicating a high level of correlation between SDF-1 1 expression and lymph-node metastasis $(\mathrm{P}=0.001)$. In addition, distant metastasis of colorectal cancer and TNM stage were related to the expression SDF- $1 \alpha(\mathrm{P}=0.007, \mathrm{P}=0.001)$.

When the relations with vascular invasion, lymphatic invasion and neural invasion were analyzed, all 11 patients who had shown vascular invasion presented a clinical profile with strong expression of SDF- $1 \alpha(\mathrm{P}=0.015)$. Out of the 18 patients with the presence of lymphatic invasion, 16 patients (89\%) had shown an expression of SDF- $1 \alpha$, a statistically significant result $(P=0.025)$. However, neural invasion of cancer cells did not show any significant relation with the expression of SDF-1 $\alpha$ (Table 2).

Relation between the expression of SDF-1 $\alpha$ and the prognosis The relation between the expression of SDF-1a and the survival rate was analyzed using follow-up observations, outpatient visits and phone calls for up to 60 months post-operatively, as a method to check on the survival of the 83 patients. The group of patients with strong expression of SDF-1a on the Kaplan-Meier's Survival curve showed poorer survival rate than the patient group with weak expression of SDF-1 $\alpha$, suggesting that the expression of SDF-1 $\alpha$ is relevant to the prognosis $(\mathrm{P}=0.021)$ (Fig. 3).

\section{DISCUSSION}

Several studies so far have reported on the role of chemokine SDF-1a/CXCR4 as a signal transduction pathway. Those studies 
Table 2. Stromal-cell-derived factor (SDF)-1a expression and the demographics

\begin{tabular}{|c|c|c|c|c|}
\hline \multirow{2}{*}{ Variable } & \multirow{2}{*}{ Patient } & \multicolumn{2}{|c|}{ SDF-1a staining pattern } & \multirow{2}{*}{ P-valu } \\
\hline & & Low & High & \\
\hline Sex & & & & 0.143 \\
\hline Male & 46 & $16(34.8)$ & $30(65.2)$ & \\
\hline Female & 37 & $10(27.0)$ & $27(73.0)$ & \\
\hline Age (yr) & & & & 0.171 \\
\hline$<60$ & 35 & $10(28.6)$ & $25(71.4)$ & \\
\hline$\geq 60$ & 48 & $16(33.3)$ & $32(66.7)$ & \\
\hline T stage & & & & 0.109 \\
\hline $\mathrm{T} 1$ & 3 & $2(66.7)$ & $1(33.3)$ & \\
\hline T2 & 7 & $4(57.1)$ & $3(42.9)$ & \\
\hline T3 & 69 & $20(29.0)$ & $49(71.0)$ & \\
\hline $\mathrm{T} 4$ & 4 & $0(0.0)$ & $4(100)$ & \\
\hline Nodal status & & & & 0.001 \\
\hline NO & 32 & $19(59.4)$ & $13(40.6)$ & \\
\hline N1 & 27 & $5(18.5)$ & $22(71.5)$ & \\
\hline N2 & 24 & $2(8.3)$ & $22(91.7)$ & \\
\hline Distant metastasis & & & & 0.007 \\
\hline MO & 50 & $21(42.0)$ & $29(58.0)$ & \\
\hline M1 & 33 & $5(15.2)$ & $28(84.8)$ & \\
\hline Stage & & & & 0.001 \\
\hline । & 9 & $7(77.8)$ & $2(22.2)$ & \\
\hline$\|$ & 25 & $13(52.0)$ & $12(48.0)$ & \\
\hline III & 44 & $6(13.6)$ & $38(86.4)$ & \\
\hline IV & 5 & $0(0)$ & $5(100)$ & \\
\hline Differentiation & & & & 0.151 \\
\hline Well & 3 & $2(66.7)$ & $1(33.3)$ & \\
\hline Moderate & 72 & $24(33.3)$ & $48(66.7)$ & \\
\hline Poor & 4 & $0(0)$ & $4(100)$ & \\
\hline Mucinous & 4 & $0(0)$ & $4(100)$ & \\
\hline Vascular invasion & & & & 0.015 \\
\hline Yes & 11 & $0(0)$ & $11(100)$ & \\
\hline No & 72 & $26(36.1)$ & $46(63.9)$ & \\
\hline Lymphatic invasion & & & & 0.025 \\
\hline Yes & 18 & $2(11.1)$ & $16(88.9)$ & \\
\hline No & 65 & $24(36.9)$ & $41(63.1)$ & \\
\hline Neural invasion & & & & 0.687 \\
\hline Yes & 1 & $0(0)$ & $1(100)$ & \\
\hline No & 82 & $26(31.7)$ & $56(68.3)$ & \\
\hline
\end{tabular}

were carried out in the areas of immunology and infection mainly; in addition, some studies addressed the roles of this ligand and its receptor in the areas of hepatopoiesis, migration of lymphocytes and human immunodeficiency virus (HIV) infection. In 2001, Müller et al. [18] reported that SDF-1 $\alpha$ was expressed from spots such as lymph nodes or bone marrow and in organs such as the 
lung, where metastasis of breast cancer frequently occurs, but it was not expressed easily in the kidney where such metastasis rarely occurs. Thereafter, because of various studies and reports, together with continuous reports on the ligand of such a pathway, SDF-1a being associated with neovascularization in malignant tumors and affecting the progression of tumors, the pathway of SDF-1 $\alpha /$ CXCR4 in malignant tumors began to attract interest.

Currently there are more than 50 chemokines, and all of them have 4 conserved cysteinyl groups with the formation of 2 essential disulphide bonds. In the beginning, this topic attracted clinical interest in diseases such as HIV/acquired immune deficiency syndrome or in the field of immunology mainly, but it has become a subject of interest as the pathways of these chemokines have become material to the treatment of cancer in recent days. Among them, a chemokine being noted with interest as the target of cancer treatment in recent days is SDF-1 $\alpha$, which is also called CXCL12. This chemokine begins signal transduction as coupling to receptors CXCR4 and CXCR7, which have the same nature [19].

SDF-1 $\alpha$ is a specific ligand to CXCR4. yet SDF-1 $\alpha$ can couple with the CXCR7 receptor. When the intra-cell molecular and physiological variations caused by the coupling with the CXCR4 receptor were investigated, which is a general coupling pattern with SDF-1 $\alpha$, SDF-1 1 w was found to couple with CXCR4 and to activate the pathway of extracellular signal-regulated kinase $1 / 2$, i.e., the phosphatidylinositol 3-kinase and mitogen-activated protein kinase pathway, such as protein kinase (B-kinase), that internalizes the flow of calcium that is being facilitated by CXCR4 inside a cell and that is involved in the migration, proliferation, fragmentation and survival of cells [20].

CXCR4 helps the interaction between cancer cells and endothelial cells by activating either the rolling of cancer cells or the endothelial cell migration of cancer cells [21]. In addition, SDF-1 $\alpha$ is considered as controlling the intra-tissue localization of cancer cells and having direct effects on the migration of cancer cells, resulting in an induction of metastasis [22]. Strieter et al. [22] reported from an in vitro study on a non-small cell lung cancer cell line that cancer cells migrated along the chemotactic gradient of SDF-1a/CXCR4. The authors in this study investigated the relations between several clinicopathological factors of patients with colon cancer, especially those between lymph-node metastasis of colorectal cancer cells and the expression of SDF-1a in order to identify the role of SDF-1 $\alpha$ in colorectal cancer, which has such molecular and physiological actions. They also investigated the relations through immunohistochemical staining of SDF-1 $\alpha$ in primary colorectal cancer tissues in order to identify the effects of the presence of SDF-1a expression on the prognosis for the patient. In addition, they performed a comparative investigation by conducting Western blot tests in order to compare the expression of SDF-1a protein in colorectal cancer cells with that in normal colorectal tissues. There had been reports from studies on the expression of SDF-1a in cancer cells that the prognosis of patients and the expression of SDF-1 $\alpha$ had shown significant relevance in neuroglioma and gastric cancer cells, but that was not the case for epithelial ovarian cancer cells or oral epidermoid carcinoma cells [23-26]. However, it should be noted that there have not been many reports so far.

The fact that the role of SDF-1a in the progression of malignant tumor is related to neovascularization in tumors has been identified in several study results. Both SDF-1 $\alpha$ and its receptor are expressed from vascular endothelial cells, and SDF-1 $\alpha$ plays an important role in gathering various bone marrow-originating CXCR4expressing cells around the tumor, such as CD11b + myelomonocyte or endothelial precursor cells [27]. On the other hand, the activations of vascular endothelial growth factor (VEGF), placenta growth factor (PlGF), VEGF receptor 1 (VEGFR1) and hypoxia inducible factor 1 alpha (HIF-1 $\alpha$ ), which triggers expression of SDF-1a locally in and around the tumor, promote recruitment of various cells originating from bone marrow through the CXCR4 pathway [28].

Consequently, by recruiting endothelial precursor cells originating from the bone marrow, which express the SDF-1a receptor, that is, the CXCR4 chemokine, around the tumor through SDF-1a expressed from tumor tissues through such processes, this ligand and receptor pathway becomes involved in neovascularization around the tumor. Although SDF-1a expression in the colorectal cancer cell line has been described in a few of previous studies, the pathological role of the SDF-1 $\alpha$ /CXCR4 axis, which is involved in the progression of colorectal cancer, in regard to its molecular mechanism is still unidentified. In addition, not many studies have addressed the expression of this cytokine in human colorectal cancer tissues so far; as a matter of fact, the authors' study is considered as being significant because of its great emphasis on SDF-1a expression in human colorectal cancer tissues.

Moreover, in the study of the authors, not only the relevance of the expression of SDF-1a to lymphatic invasion, venous invasion and lymphatic metastasis presented in patients with colorectal cancer but also the relevance to the survival rate of patients are said to have very important significance. However, unlike the results reported by the authors, results based on Northern blot tests have shown that mRNA expression of SDF-1 $\alpha$ is reduced in colorectal cancer tissues more than it is in normal colorectal tissues [29].

The study results derived by the authors demonstrate that a close relationship exists between the expression of SDF- $1 \alpha$ and the lymphnode metastasis of colorectal cancer and that such expression of chemokine in colorectal cancer is important not only for controlling deterioration of colorectal cancer but also for playing an important role in lymph-node metastasis. Furthermore, the study result of authors showed that the presence of SDF-1a expression affected the prognosis of patients with colorectal cancer and that patients with increased protein expressions of SDF-1a demonstrated lower rates of 5-year survival than patients with less expression; thus, such protein expression of SDF-1a could affect the survival rate of patients. Also, expression of SDF-1a was shown to be higher in most colorectal cancer tissues than in normal colorec- 
tal tissues through a comparison of the SDF-1 1 expressions in both tissues.

In the study of authors, it was possible to identify the clinical significance of SDF-1a expression in primary colorectal cancer tissues. This was a result of an investigation on the protein expression of SDF-1 $\alpha$, that is, a ligand of this signal transduction pathway from the primary colorectal cancer tissues, which had shown that the expression of SDF-1 $\alpha$ was related to the lymph-node metastasis of colorectal cancer and that such expression was related to the prognosis for the patient. However, the study failed to establish the fact that the angiogenesis was associated with the expression of SDF-1 $\alpha$ in colorectal cancer. Therefore, such an association should be verified in a future study.

In conclusion, from the result of this study, it was possible to identify that the expression of SDF-1a was involved in colorectal-cancer-activated lymph-node metastasis of cancer cells and that it was involved in the progression of colorectal cancer. In addition, the expression of SDF-1 1 is related to the survival rate of patients with colorectal cancer, so this molecule can be a target of colorectal cancer treatment and can be used as a prognostic factor for colorectal cancer patients. The study results of the authors establish that the SDF-1 1 chemokine can play roles as a tumor marker of lymphnode metastasis in colorectal cancer and as a mediator for expansion of the tumor; nonetheless, further studies on what roles SDF-1a may play in the metastasis of colorectal cancer and in angiogenesis are thought to be necessary.

\section{CONFLICT OF INTEREST}

No potential conflict of interest relevant to this article was reported.

\section{REFERENCES}

1. Ramsoekh D, van Leerdam ME, van Ballegooijen M, Habbema JD, Kuipers EJ. Population screening for colorectal cancer: faeces, endoscopes or X-rays? Cell Oncol 2007;29:185-94.

2. Parker SL, Tong T, Bolden S, Wingo PA. Cancer statistics, 1997. CA Cancer J Clin 1997;47:5-27.

3. Hamilton SR, Vogelstein B, Kudo S. Carcinoma of the colon and rectum. In: Hamilton SR, Aaltonen LA, editors. Pathology and genetics of tumours of the digestive system. Lyon: IARC Press; 2000. p. 105-19. (World Health Organization classification of tumours; v. 2).

4. Abdalla EK, Vauthey JN, Ellis LM, Ellis V, Pollock R, Broglio KR, et al. Recurrence and outcomes following hepatic resection, radiofrequency ablation, and combined resection/ablation for colorectal liver metastases. Ann Surg 2004;239:818-25.

5. Folkman J. The role of angiogenesis in tumor growth. Semin Cancer Biol 1992;3:65-71.

6. Bolontrade MF, Zhou RR, Kleinerman ES. Vasculogenesis plays a role in the growth of Ewing's sarcoma in vivo. Clin Cancer Res 2002;8:3622-7.
7. Lyden D, Hattori K, Dias S, Costa C, Blaikie P, Butros L, et al. Impaired recruitment of bone-marrow-derived endothelial and hematopoietic precursor cells blocks tumor angiogenesis and growth. Nat Med 2001;7:1194-201.

8. Dwenger A, Rosenthal F, Machein M, Waller C, Spyridonidis A. Transplanted bone marrow cells preferentially home to the vessels of in situ generated murine tumors rather than of normal organs. Stem Cells 2004;22:86-92.

9. Santarelli JG, Udani V, Yung YC, Cheshier S, Wagers A, Brekken $\mathrm{RA}$, et al. Incorporation of bone marrow-derived Flk-1-expressing CD34+ cells in the endothelium of tumor vessels in the mouse brain. Neurosurgery 2006;59:374-82.

10. Rafii S, Lyden D. Therapeutic stem and progenitor cell transplantation for organ vascularization and regeneration. Nat Med 2003; 9:702-12.

11. Jo DY, Rafii S, Hamada T, Moore MA. Chemotaxis of primitive hematopoietic cells in response to stromal cell-derived factor-1. J Clin Invest 2000;105:101-11.

12. De Falco E, Porcelli D, Torella AR, Straino S, Iachininoto MG, Orlandi A, et al. SDF-1 involvement in endothelial phenotype and ischemia-induced recruitment of bone marrow progenitor cells. Blood 2004;104:3472-82.

13. Jin DK, Shido K, Kopp HG, Petit I, Shmelkov SV, Young LM, et al. Cytokine-mediated deployment of SDF-1 induces revascularization through recruitment of CXCR4+ hemangiocytes. Nat Med 2006;12:557-67.

14. Schrader AJ, Lechner O, Templin M, Dittmar KE, Machtens S, Mengel M, et al. CXCR4/CXCL12 expression and signalling in kidney cancer. Br J Cancer 2002;86:1250-6.

15. Taichman RS, Cooper C, Keller ET, Pienta KJ, Taichman NS, McCauley LK. Use of the stromal cell-derived factor-1/CXCR4 pathway in prostate cancer metastasis to bone. Cancer Res 2002;62: 1832-7.

16. Uchida D, Begum NM, Almofti A, Nakashiro K, Kawamata H, Tateishi Y, et al. Possible role of stromal-cell-derived factor-1/ CXCR4 signaling on lymph node metastasis of oral squamous cell carcinoma. Exp Cell Res 2003;290:289-302.

17. Vlahakis SR, Villasis-Keever A, Gomez T, Vanegas M, Vlahakis N, Paya CV. G protein-coupled chemokine receptors induce both survival and apoptotic signaling pathways. J Immunol 2002;169: 5546-54.

18. Müller A, Homey B, Soto H, Ge N, Catron D, Buchanan ME, et al. Involvement of chemokine receptors in breast cancer metastasis. Nature 2001;410:50-6.

19. Sun X, Cheng G, Hao M, Zheng J, Zhou X, Zhang J, et al. CXCL12 / CXCR4 / CXCR7 chemokine axis and cancer progression. Cancer Metastasis Rev 2010;29:709-22.

20. Tilton B, Ho L, Oberlin E, Loetscher P, Baleux F, Clark-Lewis I, et al. Signal transduction by CXC chemokine receptor 4 . Stromal cellderived factor 1 stimulates prolonged protein kinase $B$ and extracellular signal-regulated kinase 2 activation in T lymphocytes. J Exp Med 2000;192:313-24. 
21. Darash-Yahana M, Pikarsky E, Abramovitch R, Zeira E, Pal B, Karplus R, et al. Role of high expression levels of CXCR4 in tumor growth, vascularization, and metastasis. FASEB J 2004;18: 1240-2.

22. Strieter RM, Belperio JA, Phillips RJ, Keane MP. CXC chemokines in angiogenesis of cancer. Semin Cancer Biol 2004;14:195-200.

23. Salmaggi A, Gelati M, Pollo B, Marras C, Silvani A, Balestrini MR, et al. CXCL12 expression is predictive of a shorter time to tumor progression in low-grade glioma: a single-institution study in 50 patients. J Neurooncol 2005;74:287-93.

24. Ishigami S, Natsugoe S, Okumura H, Matsumoto M, Nakajo A, Uenosono Y, et al. Clinical implication of CXCL12 expression in gastric cancer. Ann Surg Oncol 2007;14:3154-8.

25. Jiang YP, Wu XH, Shi B, Wu WX, Yin GR. Expression of chemokine CXCL12 and its receptor CXCR4 in human epithelial ovarian cancer: an independent prognostic factor for tumor progression. Gynecol Oncol 2006;103:226-33.
26. Almofti A, Uchida D, Begum NM, Tomizuka Y, Iga H, Yoshida $\mathrm{H}$, et al. The clinicopathological significance of the expression of CXCR4 protein in oral squamous cell carcinoma. Int J Oncol 2004;25:65-71.

27. Miao Z, Luker KE, Summers BC, Berahovich R, Bhojani MS, Rehemtulla A, et al. CXCR7 (RDC1) promotes breast and lung tumor growth in vivo and is expressed on tumor-associated vasculature. Proc Natl Acad Sci U S A 2007;104:15735-40.

28. Du R, Lu KV, Petritsch C, Liu P, Ganss R, Passegué E, et al. HIFlalpha induces the recruitment of bone marrow-derived vascular modulatory cells to regulate tumor angiogenesis and invasion. Cancer Cell 2008;13:206-20.

29. Shibuta K, Begum NA, Mori M, Shimoda K, Akiyoshi T, Barnard GF. Reduced expression of the CXC chemokine hIRH/SDF-1alpha mRNA in hepatoma and digestive tract cancer. Int J Cancer 1997; 73:656-62. 